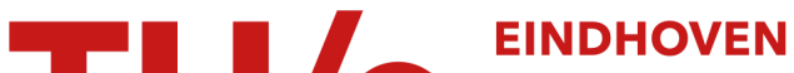 UNIVERSITY OF TECHNOLOGY
}

\section{Business process redesign : A Petri-net-based approach}

Citation for published version (APA):

Aalst, van der, W. M. P., \& Hee, van, K. M. (1996). Business process redesign : A Petri-net-based approach. Computers in Industry, 29(1-2), 15-26. https://doi.org/10.1016/0166-3615(95)00051-8

DOI:

10.1016/0166-3615(95)00051-8

Document status and date:

Published: 01/01/1996

\section{Document Version:}

Publisher's PDF, also known as Version of Record (includes final page, issue and volume numbers)

\section{Please check the document version of this publication:}

- A submitted manuscript is the version of the article upon submission and before peer-review. There can be important differences between the submitted version and the official published version of record. People interested in the research are advised to contact the author for the final version of the publication, or visit the $\mathrm{DOI}$ to the publisher's website.

- The final author version and the galley proof are versions of the publication after peer review.

- The final published version features the final layout of the paper including the volume, issue and page numbers.

Link to publication

\section{General rights}

Copyright and moral rights for the publications made accessible in the public portal are retained by the authors and/or other copyright owners and it is a condition of accessing publications that users recognise and abide by the legal requirements associated with these rights.

- Users may download and print one copy of any publication from the public portal for the purpose of private study or research.

- You may not further distribute the material or use it for any profit-making activity or commercial gain

- You may freely distribute the URL identifying the publication in the public portal.

If the publication is distributed under the terms of Article 25fa of the Dutch Copyright Act, indicated by the "Taverne" license above, please follow below link for the End User Agreement:

www.tue.nl/taverne

Take down policy

If you believe that this document breaches copyright please contact us at:

openaccess@tue.nl

providing details and we will investigate your claim. 


\title{
Business process redesign: A Petri-net-based approach
}

\author{
W.M.P. van der Aalst ${ }^{*}$, K.M. van Hee \\ Department of Mathematics and Computing Science, Eindhoven University of Technology, P.O. Box 513, 5600 MB, Eindhoven, The \\ Netherlands
}

\begin{abstract}
Reengineering business processes seems to be a necessity in order to survive and prosper in today's competitive world. To support business process reengineering (BPR) efforts, we propose a framework based on high-level Petri nets. This framework is used to rnodel and analyse business processes. The use of high-level Petri nets provides us with advanced analysis techniques and sophisticated software tools.

To support the use of this Petri-net-based framework, we also present the "What, how and by whom?" approach. This approach has been developed to guide the application of the framework in a BPR setting. The "What, how and by whom?" approach identifies three important stages in the (re)design of a business process. By passing through these stages we obtain a complete Petri net model of the current (As-is) or proposed (To-be) situation, whereupon Petri-net-based analysis techniques can be used to verify the correctness and estimate the performance of the (re)designed business process.
\end{abstract}

Keywords: Business process redesign; High-level Petri nets; Application of Petri nets

\section{Introduction}

An increasing number of firms are marching to the drumbeat of business process redesign (BPR), alternatively called reengineering. The term reengineering may be new, but the idea of process redesign is familiar to most engineers involved in logistics and production control. Just-in-time (JIT), total quality management (TQM), flexible manufacturing systems (FMS), computer integrated manufacturing (CIM) and computer integrated logistics (CIL) are some of the buzz words used to signify process redesign trends in logistics and manufacturing control. However, business process redesign is not restricted to logistics and manufacturing, it also applies to administrative, commercial and managerial pro-

\footnotetext{
${ }^{*}$ Corresponding author.
}

cesses. Nevertheless, we think that many of the techniques, tools and methods developed for logistics and production control can be used in the context of business process redesign.

Business process redesign focuses on the fundamental rethinking of business processes, ignoring organisational boundaries. However, before implementing new business processes, we want to compare the existing situation with the new (redesigned) situation. Therefore, we need a tool to quickly capture and model existing processes as well as new processes. This tool should support rigorous changes and catalyze creative thinking. Moreover, we would like to use this tool to analyse and compare alternative business processes.

In this paper high-level Petri nets are proposed as a tool for the modelling and analysis of business processes. Petri nets have proved to be useful in the 
context of logistics and production control [1,2]. However, the application of these Petri nets is not restricted to logistics and manufacturing, they can also be used to support business process reengineering efforts.

High-level Petri nets are based on the classical Petri net model introduced by Carl Adam Petri [3]. The high-level Petri net model used in this paper is extended with "colour", "time" and "hierarchy". These extensions allow for the representation and study of complex business processes. The high-level Petri net inherits all the advantages of the classical Petri net, such as the graphical and precise nature, the firm mathematical foundation and the abundance of analysis methods. Clearly, the graphical nature of Petri nets is a very important feature in the context of business process redesign.

To support the use of high-level Petri nets for reengineering purposes, we have developed the "What, how and by whom?" approach. This approach identifies three consecutive phases in the application of high-level Petri nets to business process redesign. In the "what" phase the primary objectives of a company or business unit are investigated. In the second phase, it is determined how these objectives can be reached. This phase is used to identify the required activities and the ordering of these activities. In the "by whom" phase the allocation of resources (e.g., manpower and machines) to these activities is determined.

The remainder of this paper is organised as follows. We start with a short introduction to business process redesign, followed by an introduction to high-level Petri nets. Then we show how the "What, how and by whom?"' approach can be used to map business processes onto a high-level Petri net. This is illustrated by an example.

\section{Business process (re)design}

Reengineering business processes means tossing aside existing processes and starting over. In Hammer and Champy [4] business process redesign (reengineering) is defined as "the fundamental rethinking and radical redesign of business processes to achieve dramatic improvements in critical contemporary measures of performance such as costs, qual- ity and speed". This definition contains four key words:

- Fundamental. Reevaluate the primary goals of the company, ignoring rules and assumptions formulated in the past.

- Radical. Do not try to improve the existing situation, invent completely new ways of accomplishing work.

- Dramatic. Do not use business process redesign to obtain marginal improvements, aim at "order of magnitude" improvements.

- Process. Focus on the business processes instead of organisational structures.

So, in a nutshell, business process redesign (BPR) is an ambitious and rule-breaking approach focusing on business processes instead of organisational boundaries.

In this paper we will concentrate on rethinking business processes. We will not discuss the organisational aspects of BPR, the role of information technology or management and training issues. For discussions on these other important subjects, the reader is referred to Davenport [5], Hammer [6], Hammer and Champy [4] and Morris and Brandon [7]. By narrowing BPR down like this, three important themes emerge: what, how and by whom? (Fig. 1).

\subsection{What?}

What are the prime objectives of a company or business unit? An attempt to reengineer a business process should always start with this question.

Consider for example an automobile insurance company having problems with the processing of claims because of the control step to avoid overbilling. Is it really necessary to check every claim? The objective of the insurance company is to reduce costs while keeping the customers happy. Therefore, it is not necessary to approve every claim before the repair takes place. Select a number of garages that are checked periodically. This way costs can be reduced while keeping the customers happy (damage is repaired instantly).

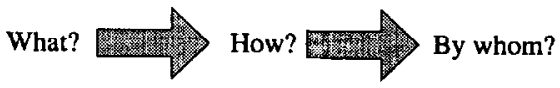

Fig. 1. What, how and by whom? 
Another example is a truck company having problems with the distribution of spare parts because regional distribution centres are running out of stock frequently. By increasing the inventory levels in the regional distribution centres, we can improve the customers service but the costs of stock keeping will rise. However, do we really need these regional distribution centres? By investing in rapid transport, it may suffice to have only one central distribution centre.

These examples show that we should always ask the basic question: "Why do we do what we do?".

\subsection{How?}

When we have determined what a company should do, we have to determine how to do it. Again we should not be hampered by existing rules and assumptions. Processes, not organisations, are the object of BPR. Processes in a company correspond to natural business activities, but they are often fragmented and obscured by organisational structures. If we have found a process to be redesigned, we should give this process a name and determine the input and output of the process. Then we determine the work that has to be done between the start and finish of the process, i.e. all the required steps are identified. We can think of a such step as a task or an activity. Then we determine the ordering of these steps, e.g. task $a$ has to be executed before task $b$, but $a$ can be executed in parallel with task $c$. In Hammer and Champy [4] a number of guidelines are given to support this activity:

- The steps in a process should be performed in a natural order.

- Avoid fragmentation of related activities.

- If possible, several steps are combined into one.

- If possible, tasks are allowed to be executed in parallel.

- Avoid complex processes to cope with complex activities.

- Reduce checks and controls as much as possible.

- Make processes generic, i.e. use multiple versions of the same procedure.

- Check whether modern information technology allows you to omit steps.

The result of applying these guidelines will be a partially ordered set of tasks or steps. We will use the term procedure to refer to this result. Note that a procedure does not determine who is doing the work, i.e. a procedure is just a recipe.

\subsection{By whom?}

Finally, we have to decide who is going to do the work and in what order. By allocating resources (often employees) to tasks, we are scheduling the business process. We can use advanced scheduling techniques to optimize this allocation. However, in practice simple and robust heuristics are more appropriate. Therefore, we list a number of guidelines to support the construction of these heuristics.

- Reduce the number of people involved in the execution of tasks related to one job. Thus avoiding communication and set-ups.

- Tasks are performed where they make the most sense.

- There should be a balance between specialisation and generalisation.

- There should be a balance between centralisation and decentralisation.

Since Adam Smith's The Wealth of Nations [8], people have been attempting to break work into its simplest and most basic tasks. Due to this specialisation, the processes have become very complex. As a result the business processes have become hard to manage, thus causing long processing times and a lot of work-in-progress. Replacing specialists by generalists allows for a simplification of the business processes.

Modern information technology allows companies to balance between centralisation and decentralisation. This way business units can be autonomous while still enjoying the benefits of centralised control (e.g., economies of scale).

This concludes our discussion on business process redesign. We have seen that the rethinking of busi-

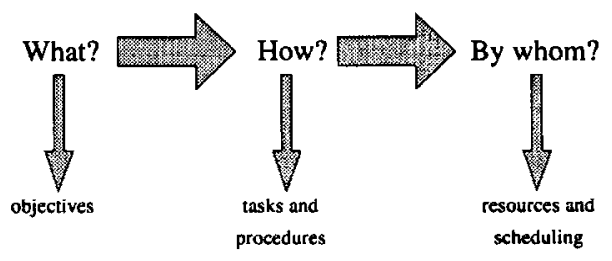

Fig. 2. What, how and by whom? 
ness processes boils down to answering the "What, how and by whom?' question (Fig. 2). In the remainder we will concentrate on a formalism to support this task.

\section{High-level Petri nets}

As indicated by Hammer and Champy [4], BPR is characterised by four keywords: fundamental, radical, dramatic and process. Therefore we need a framework for modelling processes which forces the user to examine the core of the business process, thus supporting radical and dramatic changes.

In this paper we use a framework based on highlevel Petri nets. We will show that this framework can be used to model and analyse business processes.

\subsection{The classical Petri net model}

Historically speaking, Petri nets originate from the early work of Carl Adam Petri [3]. Since then the use and study of Petri nets have increased considerably. For a review of the history of Petri nets and an extensive bibliography the reader is referred to $\mathrm{Mu}$ rata [9].

The classical Petri net is a directed bipartite graph with two node types called places and transitions. The nodes are connected via directed arcs. Connections between two nodes of the same type are not allowed. Places are represented by circles and transitions by rectangles with a marked corner (In literature transitions are often displayed as bars). The marked corner is used to distinguish transitions from subnets, see Section 3.2. Places may contain zero or more tokens, drawn as black dots. The number of tokens may change during the execution of the net. A place $p$ is called an input place of a transition $t$ if there exists a directed arc from $p$ to $t, p$ is called an output place of $t$ if there exists a directed arc from $t$ to $p$.

We will use the net shown in Fig. 3 to illustrate the classical Petri net model. This figure models a clerk that has been assigned to process certain documents (e.g., checking the credit-worthiness of a person applying for a mortgage). There are five places (d_in, c_free, c_busy, d_proc and d_out) and two transitions (start and finish). In the

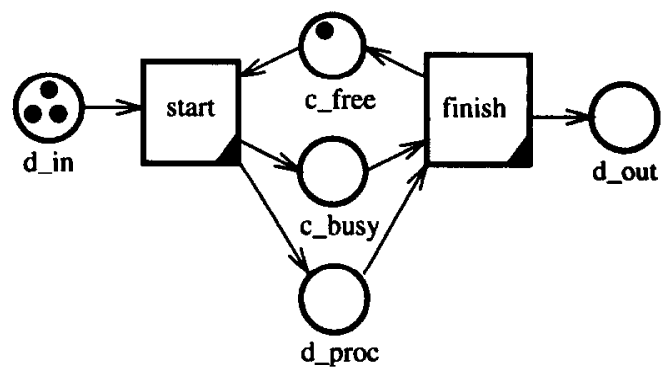

Fig. 3. A classical Petri net which represents a clerk processing documents.

state shown in Fig. 3 there are four tokens; three in place $d \_$in and one in place $c \_f r e e$. The tokens in place d_in represent documents to be processed by the clerk. The token in place c_free indicates that the clerk is free and ready to process a document. If the clerk is processing a document, then there are no tokens in C_free and there is one token in c_busy. A token in d_proc represents a document that is being processed by the clerk. Tokens in place d_out represent documents which have been processed by the clerk. Transition start has two input places (d_in and c_free) and two output places (c_busy and d_proc). Transition finish has two input places (c_busy and d_proc) and two output places (d_out and c_free).

A transition is called enabled if each of its input places contains "enough" tokens. An enabled transition can fire. Firing a transition $t$ means consuming tokens from the input places and producing tokens for the output places, i.e. $t$ "occurs".

Transition start is enabled in the state shown in Fig. 3, because each of the input places (d_in and c_free) contains a token. Transition finish is not enabled because there are no tokens in place c_busy. Therefore, transition start is the only transition that can fire. Firing transition start means consuming two tokens, one from d_in and one from $c$ free, and producing two tokens: one for c_busy and one for d_proc. The resulting state is shown in Fig. 4. In this state only transition finish is enabled. Hence, transition finish fires and the tokens in places c_busy and d proc are consumed and two tokens are produced, one for d_out and one for c_free. Now transition start is enabled, etc. Note that as long as there are docu- 


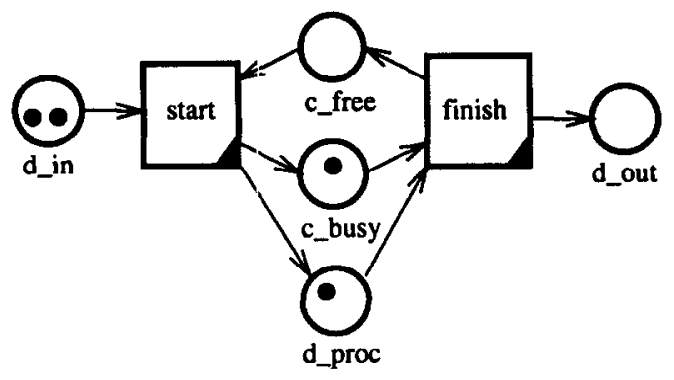

Fig. 4. The state after firing start.

ments waiting to be processed, the two transitions fire alternately, i.e. the clerk modelled by this net can only process one document at a time.

\subsection{Adding colour, time and hierarchy}

The classical Petri net model has been used in many application areas, e.g., communication protocols, flexible manufacturing systems and distributed information systems [9]. However, Petri nets describing real systems tend to be complex and extremely large. To solve these problems, many authors propose extensions of the basic Petri net model. We will discuss three of these extensions; "colour", "time" and "hierarchy". Such extensions are a necessity for the successful application of Petri nets to the modelling of large and complex business processes. Since the addition of colour, time and hierarchy has been discussed in a previous issue of Computers in Industry [1], we confine ourselves to just a few hints.

Tokens often represent objects (e.g., documents, resources, goods, humans) in the modelled system. Therefore, we often want to represent attributes of these objects. In a Petri net extended with colour, each token has a value often referred to as "colour". In Fig. 5 we see that a token which represents a clerk, i.e. a token in c_free or c_busy, has a value indicating the name, age and years of experience of the clerk. Tokens in the places d_in, d_proc and d_out have a value indicating the number, status and contents of a document.

In a Petri net extended with time, tokens also have a timestamp (see Fig. 5). This way it is possible to model the temporal behaviour of processes. Because of this extension it is possible to analyse the performance of business processes modelled in terms of Petri nets.

Although timed, coloured Petri nets allow for a succinct description of many business processes, precise specifications for real systems have a tendency to become large and complex. This is the reason why we provide a hierarchy construct, called system. A system is an aggregate of places, transitions and (possibly) subsystems. Fig. 6 shows a model of two clerks processing documents in parallel. Each of the clerks is modelled by a system composed of three places and two transitions. Systems are connected to places by means of connectors.

In the remainder of this paper we will refer to Petri nets extended with "colour", "time" and "hierarchy" as high-level Petri nets. For more information on these nets, the reader is referred to $[1,10-12]$.

\subsection{Analysis of Petri nets}

The complexity of the design and control problems encountered in modern business processes is increasing. Therefore, we need methods and techniques to support both the modelling and analysis of these processes. High-level Petri nets often allow for a representation which is close to the problem situation, i.e. it is possible to make a "blueprint" of the business process in a natural manner. This representation can be used as a starting point for various kinds of analysis. In a sense, the Petri net representation scrves as a "solver-independent" medium between the problem situation and the method(s) of analysis.

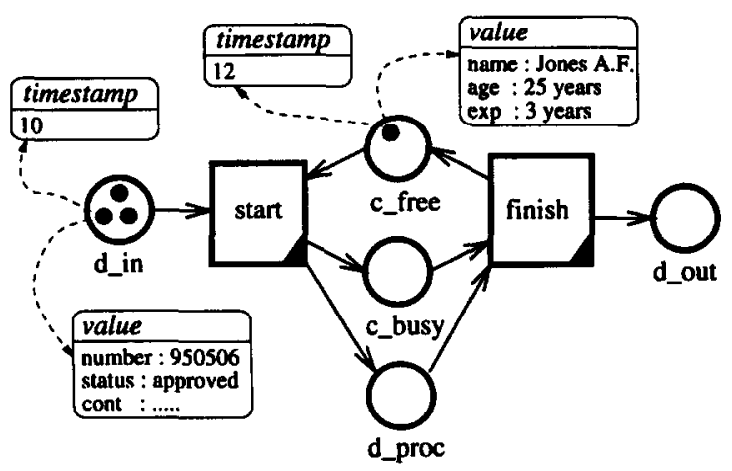

Fig. 5. Adding colour and time. 
Compared to many other BPR tools (cf. Bradley et al. [13]) analysis is not restricted to simulation! For an overview of the many analysis methods developed for Petri nets the reader is referred to Jensen [12], Murata [9], and [10,14]. These methods can be used to prove properties (safety properties, invariance properties, deadlock, etc.) and to calculate performance measures (response times, waiting times, occupation rates, ctc.). In this way it is possiblc to evaluate alternative designs.

The approach described in this paper is based on the software package ExSpect (Executable Specification Tool). ExSpect has been developed by the Information Systems department of Eindhoven University of Technology [10,11]. ExSpect provides a graphical interface to create, modify and simulate high-level Petri nets, analysis tools and reporting facilities. Since 1992, ExSpect is being distributed by Bakkenist ${ }^{1}$.

\section{Mapping business processes onto high-level Petri nets}

High-level Petri nets are suitable for the modelling and analysis of business processes. By using a Petri-net-based framework, we are able to abstract from organisational aspects. To illustrate the application of Petri nets to BPR, we will show how these nets can be used to answer the "What, how and by whom?', question formulated in Section 2.

\subsection{What?}

After selecting a business process to be redesigned, we determine the boundaries of this process. The input and output which pass this boundary signify the meaning of this process for the company. By focusing on the input and output of a business process, we should be able to distil the prime objectives of this process.

Business processes are mapped onto systems. The business process to be reengineered is modelled by an open system, i.e. a net exchanging tokens with

\footnotetext{
${ }^{1}$ Bakkenist Management Consultants, Wisselwerking 46, 1112 XR, Diemen, The Netherlands.
}

some environment. We can determine what a business process should do by observing the relevant interactions with the environment, i.e. input and output are investigated to determine the prime objectives. Modelling a business process by a system forces us to reconsider the prime objectives of a business process.

To illustrate the mapping of business processes onto high-level Petri nets, we use a business process in an automobile insurance company having problems with the processing of claims. The process check_claim handles claims related to car damage. If a claimant reports car damage, this process checks whether the claim is justified. The input of this business process is the inflow of claims of people having car damage, the output is the outflow of claims that have been screened. The process check_claim is modelled by a system with the same name. Fig. 7 shows that this system has one input place (claim) and two output places (accepted_claim and rejected_claim). Tokens in these places represent claims. Place claim contains claims that have to be checked. Claims in place accepted_claim have been checked and turned out to be justified. Claims in place rejected_claim have not been accepted for some reason.

\subsection{How?}

If we have determined the input and output of a business process, we focus on the work that has to be done between the start and finish of the process. First, we identify the steps that are required to do the work. Then we consider the ordering of these steps. We will use the term task instead of the term step. A task is atomic, which means that it is considered as an indivisible amount of work. Examples of tasks are: typing a letter, making a telephone call, signing a document and making an invoice. A business process is composed of a number of tasks, these tasks have to be executed in a particular order.

Tasks are mapped onto transitions. Each task corresponds to a transition in the system which represents the business process to be reengineered. These transitions are linked together by places and other transitions, thus defining a partial ordering of tasks. This way, we define how the business process 

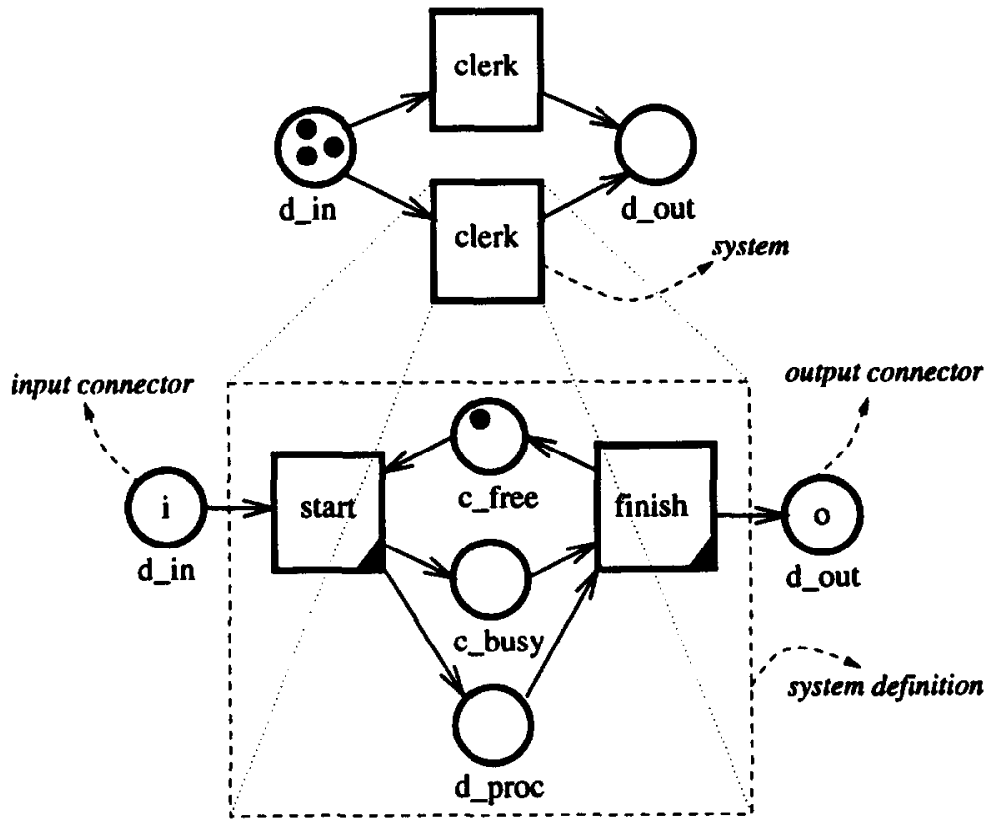

Fig. 6. Two clerks processing documents in parallel.

should work. At this moment we do not bother about who is going to process these tasks, we only determine the tasks required and the ordering of these tasks.

The process check_claim requires three tasks: check_insurance, contact_garage and ok?. The task check_insurance is executed to check whether the claimant is insured for the damage reported. The task contact_garage is performed to inquire about the damage. If these two tasks have been performed, a decision has to be made (transition ok?); the clairn is accepted or not. If transition ok? fires, it produces one token. This token is placed in output place accepted_claim or in

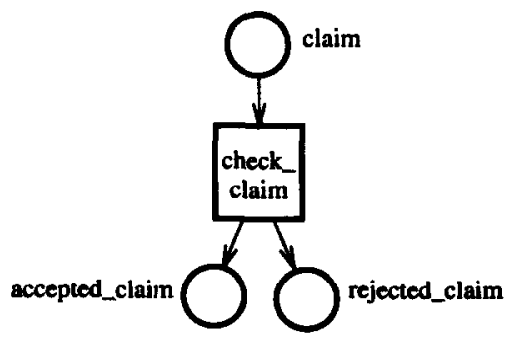

Fig. 7. The process check_claim. output place rejected_claim, depending on the results of the two checks.

Fig. 8 shows a possible business process com-

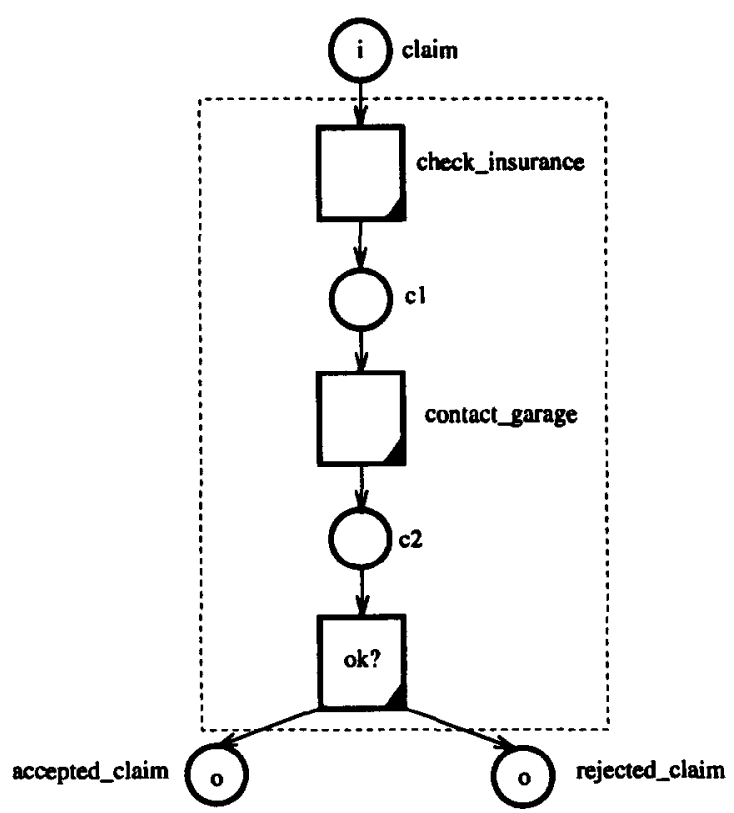

Fig. 8. The process check_claim (alternative 1). 


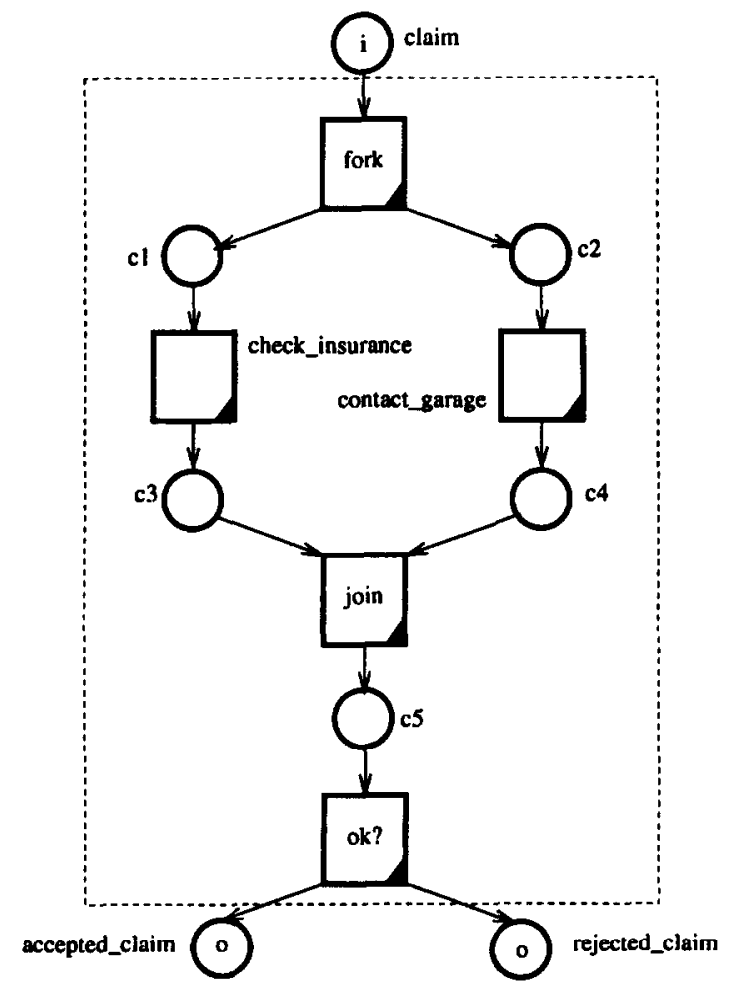

Fig. 9. The process check_claim (alternative 2).

posed of these three tasks. The tasks are executed sequentially; first check_insurance, then contact_garage and finally ok?. The tasks are represented by transitions and are linked together by the places $c 1$ and $c 2$. Tokens in these two places correspond to claims being processed. The value of such a token contains information about the claim, e.g., claim number, name and address of claimant, license number, etc.

It is not a requirement that the three tasks are executed sequentially. The tasks check_insurance and contact_garage may bc executcd in parallel. Fig. 9 shows an alternative business process where these two tasks are executed in parallel. The transitions fork and join do not represent tasks; they have been added to allow the tasks check_insurance and contact_garage to be executed in parallel. Transitions such as fork and join represent control activities. Control activities are used for the routing of work, synchronisation, etc.
The places in a system which represents a business process are used to model the flow of work. Tokens in these places represent documents, signals, goods, forms, etc. The value of such a token contains information about the object represented by the token. Most tokens have some unique identity, e.g. a document number or a case number. Procedures are represented by systems. Systems may be composed of subsystems (see Section 3.2 and [1]). Therefore, it is possible to nest procedures, i.e. a complex procedure may be composed of less complex procedures.

The result of the "how" phase is a partially ordered set of tasks, represented in terms of a Petri net. In this phase we do not bother about who is going to execute these tasks. Therefore, we will use the term procedure instead of process. Figs. 8 and 9 show two alternative procedures for the process check_claim.

Petri nets allow for many analysis techniques. We can use these techniques to analyse business procedures modelled in terms of a Petri net. We can use Petri net theory to verify the correctness of a procedure, e.g., absence of deadlock, invariance properties, termination, etc. In fact, we can prove that, for an external observer, the two procedures shown in Figs. 8 and 9 behave (logically) the same!

\subsection{By whom?}

A procedure does not determine who is doing the work, e.g. Fig. 9 does not specify which employee will check the insurance of the claimant. In the "by whom" phase we decide who is going to do the work and in what order. By allocating resources to tasks, we are scheduling the business process. We use the term resource to denote some entity capable of processing certain tasks, e.g., a person or a machine.

Resources are able to perform a limited set of tasks. A resource class is a set of similar resources. Each task requires resources from a given resource class. A group of telephone operators, a group of office employees and a group of claim appraisers are examples of resource classes.

In the "by whom" phase we have to specify the link between tasks and resources, i.e. we have to describe a resource manager which assigns resources to tasks. The resource manager controls the 
allocation of resources. A resource manager can be a person, a computer system or a combination of the two.

In Fig. 9 we have abstracted from the fact that there are resources. When we define a procedure, we assume that the task's are executed instantly. In reality this is not the case, some time passes between the moment a task emerges and the moment it is executed. Therefore, we have to model tasks by systems instead of transitions. In Fig. 9, we have to replace the transitions check_insurance, contact_ garage and ok? by three systems. Each of these systems is composed of two transitions and one place, see Fig. 10. Transition execute fires when the task is activated by a token in the place connected to output connector cin. Transition complete fires when the task has been completed and produces a token for the place connected to output connector cout. The output connector execute_task and the input connector task_completed are connected to a resource manager. If transition execute fires, a token is sent to the resource manager via output connector execute_task. The value of this token contains information about the task to be executed, e.g., identification, workload and resource class. (We also use the term task to denote a task instance.) When this task has been executed, the resource manager sends a token to the task vila input connector task_completed. The tokens in place et represent tasks that

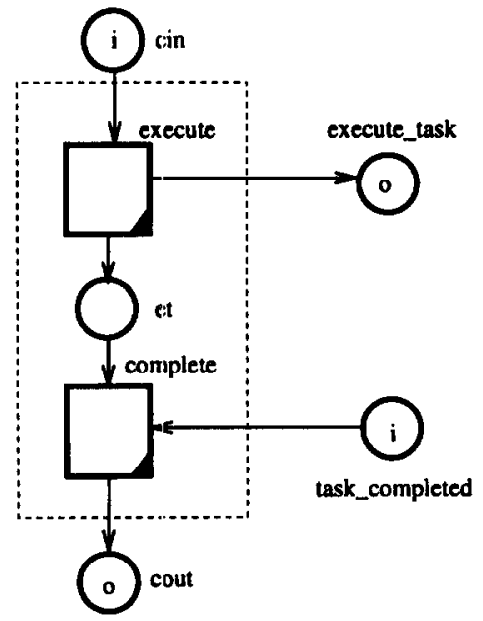

Fig. 10. A task is a system composed of two transitions.

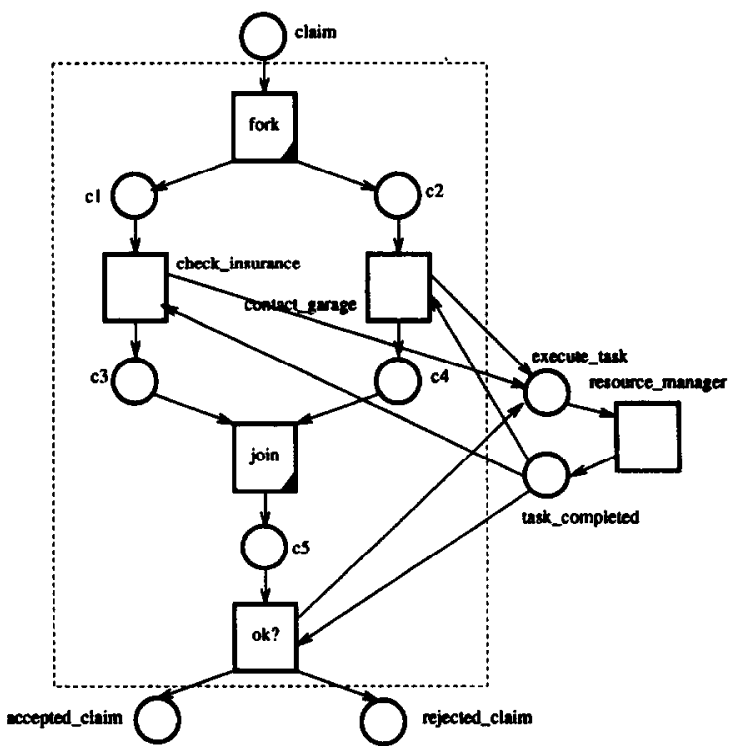

Fig. 11. The process check_claim with resources.

have not been completed yet. Transition complete has a precondition which makes sure that the proper task is removed from place et when a token arrives via input connector task_completed.

If we replace each transition which represents a task by a system, we obtain the Petri net shown in Fig. 11. The resource manager is also modelled by a system and the places execute_task and task_completed have been added to enable the communication between the tasks and the resource manager. In this case the tasks check_insurance, contact garage and ok? are connected to the same resource manager. However, it is also possible to have multiple resource managers.

A token exchanged via execute_task has a value which contains information about the task to be executed. The value of such a token is typically composed of:

1. a job identification, tasks are executed on behalf of a specific case (e.g., a claim, an article, an order);

2. a task identification, the name or the code of a task;

3. a resource class, a task requires a resource from a specific resource class; and

4. some additional information about the task to be executed (e.g., priorities, due dates). 


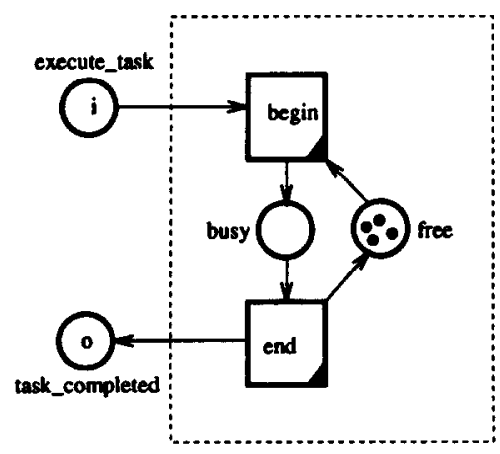

Fig. 12. A very simple resource manager.

The resource manager uses this information to schedule the tasks to be executed.

A resource manager is a scheduler which allocates resources to tasks, i.e. it decides who is going to do the work and in what order. We can use advanced scheduling techniques to optimize this allocation. However, in practice simple and robust heuristics are more appropriate. Fig. 12 shows a system which models a very simple resource manager. In this case, each resource is modelled by a token in free or busy. A token in place free corresponds to a resource which is ready to execute a task. A token in busy corresponds to a resource which is busy executing a task. The tokens in the input place execute_task represent tasks waiting to be executed. Transition begin fires when a resource starts processing a task. Transition begin has a precondition which makes sure that a resource from the proper resource class is allocated to the task to be executed. The tasks are executed in first-in first-out
(FIFO) order. If transition begin fires, then it produces a token for place busy with a delay. This delay corresponds to the time required to execute the task. Transition end fires when a task has been executed.

We can also model a resource manager which uses advanced scheduling techniques. In this case, the resource manager uses more information about the task to be schcduled. By assigning a priority to each task, we can favour an important task above less important tasks. We can use most of the priority rules for rule-based scheduling [15]. Typical priority rules are: SPT (shortest processing time), MWKR (most work remaining), LWKR (least work remaining), DD (earliest due date), etc.

Fig. 11 looks rather complicated because of the connections between the tasks and the resource manager. However, we can automate the construction of this part of the figure. We only have to describe the procedure (see Fig. 9) and the scheduling rules used by the resource manager to specify the business process completely.

\subsection{Example}

By modelling a procedure and a resource manager we are able to analyse the resulting business process. Petri-net-based analysis techniques can be used to evaluate the performance of the modelled business process. We can use these techniques to calculate the estimated throughput of a process, the average throughput time of a job, the estimated occupation

Table 1

Some simulation results

\begin{tabular}{|c|c|c|c|c|c|c|c|c|}
\hline \multirow[t]{3}{*}{ Subrun } & \multicolumn{2}{|c|}{ Average throughput time } & \multicolumn{6}{|c|}{ Occupation rate } \\
\hline & \multirow[t]{2}{*}{ Alternative 1} & \multirow[t]{2}{*}{ Alternative 2} & \multicolumn{3}{|c|}{ Alternative 1} & \multicolumn{3}{|c|}{ Alternative 2} \\
\hline & & & Cindy & John & Laura & Cindy & John & Laura \\
\hline 2 & 13.19 & 11.33 & 41.3 & 35.2 & 40.2 & 37.2 & 40.7 & 40.8 \\
\hline 3 & 13.42 & 10.97 & 41.5 & 35.7 & 40.3 & 37.2 & 40.9 & 40.9 \\
\hline 6 & 13.31 & 10.61 & 41.1 & 35.6 & 40.1 & 36.9 & 41.4 & 41.1 \\
\hline 7 & 13.27 & 10.50 & 41.2 & 35.7 & 40.2 & 37.3 & 41.0 & 41.3 \\
\hline 8 & 13.25 & 10.75 & 41.3 & 35.3 & 40.4 & 37.0 & 41.2 & 41.4 \\
\hline 9 & 13.27 & 10.98 & 41.7 & 35.2 & 40.6 & 37.6 & 41.1 & 41.0 \\
\hline 10 & 13.50 & 10.97 & 41.6 & 35.8 & 40.5 & 37.3 & 41.2 & 40.9 \\
\hline
\end{tabular}


rate, etc. For example, we are able to compare the performance of the two procedures shown in Figs. 8 and 9 (given a workload and a scheduling discipline).

Assume that the arrival of claims that have to be checked by the process check_claim can be described by a Poisson arrival process (i.e. the time between two arrivals is negative exponentially distributed). The average time between two arrivals is 10 minutes. Moreover, there are three office employees; Cindy, John and Laura. Cindy is qualified to contact the garage (task contact_garage), John can do two types of tasks: check_insurance and ok?. Laura is the orlly one qualified to do all three types of tasks. We assume that the time required to execute a task is independent of the person executing the task. Task contact_garage takes between 5 and 7 minutes (uniformly distributed). The other two tasks take between 2 and 4 minutes (uniformly distributed).

We use simulation to compare the two procedures described in Section 4.2. During the simulation of these two alternatives, we measured the average throughput time of claims and the occupation rate of each office employee. Table 1 reports the average throughput time of claims and the occupation rates for each of the two alternatives. This table shows that alternative 2 is preferable. The average throughput time of claims is reduced by the parallel execution of the tasks contact_garage and check insurance. In both alternatives, the workload is balanced over the employees.

We have used the Petri-net-based tool ExSpect $[10,11]$ to obtain the results presented in Table 1 . By using this tool we can model both alternatives in half an hour. Simulating one alternative for 70 days takes about 5 minutes on a: SUN/SPARC workstation.

\section{Conclusion}

Several other teclnniques have been proposed to support business process reengineering efforts. Diagramming techniques such as flowcharts, decision trees, Warnier-Orr diagrams, state transition diagrams, fishbone diagrams, hierarchy charts, dataflow diagrams and business activity maps [7] have been used to represent business processes. Most of these techniques suffer from two important drawbacks: (1) the lack of formal semantics and (2) the absence of powerful analysis methods and tools.

High-level Petri nets have formal semantics. A Petri net model of a business process is a precise and unambiguous description of the behaviour of the modelled process. The precision and the firm mathematical foundation of Petri nets have resulted in an abundance of analysis methods and tools.

Despite the formal background, Petri nets are easy to understand. The graphical nature can be used to visualise business processes in a natural manner and supports the communication between people involved in a BPR project.

The "What, how and by whom?" approach presented in this paper can be used to model business processes in a step by step manner. Improving an existing business process requires a thorough understanding of this process. This can be achieved by modelling the "As-is" process. The model of the "As-is" process can be used as a stepping stone for models of "To-be" alternatives. Analysis techniques, such as simulation, can be used to compare the "As-is" model with the "To-be" models.

\section{References}

[1] W.M.P. van der Aalst, "Putting Petri nets to work in industry", Computers in Industry 25(1) (1994) 45-54.

[2] K. Jensen and G. Rozenberg (eds.), High-level Petri Nets: Theory and Application, Springer-Verlag, Ncw York, 1991.

[3] C.A. Petri, Kommunikation mit Automaten, $\mathrm{PhD}$ thesis, Institut für instrumentelle Mathematik, Bonn, 1962.

[4] M. Hammer and J. Champy, Reengineering the Corporation, Nicolas Brealey Publ., London, 1993.

[5] T.H. Davenport, Process Innovation: Reengineering Work through Information Technology, Harvard Business School Press, Boston, MA, 1993.

[6] M. Hammer, "Reengineering work: Don't automate, obliterate", Harv. Bus. Rev. (July/August 1990) 104-112.

[7] D. Morris and J. Brandon, Reengineering your Business, McGraw-Hill, New York, 1993.

[8] A. Smith, The Wealth of Nations, 1776.

[9] T. Murata, "Petri nets: Properties, analysis and applications", Proc. IEEE 77(4) (April 1989) 541-580.

[10] W.M.P. van der Aalst, "Timed coloured Petri nets and their application to logistics", $\mathrm{PhD}$ thesis, Eindhoven University of Technology, Eindhoven, 1992.

[11] K.M. van Hee, Information System Engineering: A Formal Approach, Cambridge University Press, 1994.

[12] K. Jensen, Coloured Petri Nets - Basic Concepts, Analysis Methods and Practical Use, EATCS monographs on Theoretical Computer Science, Springer-Verlag, New York, 1992. 
[13] P. Bradley, J. Browne, S. Jackson and H. Jagdev, “Business process reengineering (BPR): A study of the software tools currently available", Computers in Industry 25(3) (1995) 309-330.

[14] W.M.P. van der Aalst, "Interval timed coloured Petri nets and their analysis", in: M. Ajmone Marsan (ed.), Application and Theory of Petri Nets 1993, (Lecture Notes in Conpuler Science 691), Springer-Verlag, New York, 1993, pp. 453-472.

[15] R. Haupt, "A survey of priority rule-based scheduling", $O R$ Spectrum 11 (1989) 3-16.

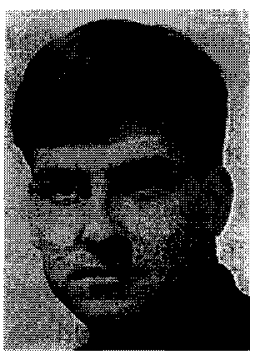

Wil van der Aalst is an Assistant Professor in the Department of Mathematics and Computing Science at Eindhoven University of Technology. In 1992, he completed his PhD thesis on Petri nets and their application to logistics. His research interests are in simulation, information systems, business process redesign, manufacturing and real time systems. He is also working as a part-time consultant for Bakkenist Management Consultants.

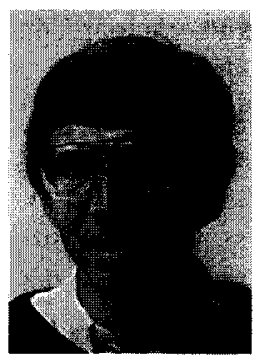

Kees van Hee studied Mathematics at the University of Leiden, In 1978 he completed his PhD thesis in the area of Operations Research. From 1978 till 1984 he was managing director of AKB bv in Rotterdam. Since 1984 he is a professor of Computing Science at Eindhoven University of Technology. His research interests are in formal and executable specifications for distributed (information) systems, workflow manage ment systems and (interactive) planning systems. Since 1994 he is also a member of the board of directors of Bakkenist Management Consultants. 